\title{
Sustainability Practices for Urban Housing Societies
}

\author{
Saha Dauji* \\ Nuclear Recycle Board, Bhabha Atomic Research Centre, India
}

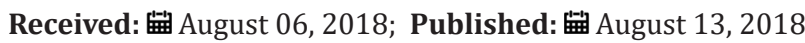

*Corresponding author: Saha Dauji, Nuclear Recycle Board, Bhabha Atomic Research Centre, Mumbai, India \& Homi Bhabha National Institute, Mumbai, India

\begin{abstract}
Individual bungalows have given way to housing society in urban localities, where the floor area ratio is very high, most of the exposed areas are covered as pavements or parking spaces, and the population density is also very high. The pressures of modern life keep people from making intelligent and thoughtful decisions and thereby they fall prey to unsustainable social and environmental practices at their homes. A little awareness and effort from the housing society management bodies and cooperation from the residents would contribute to remedy this at the housing society level. This would set a strong example for all others to follow. Such sustainable practices, when adopted and implemented at different levels, would improve the living conditions and habitability in urban communities.
\end{abstract}

Keywords: Sustainability; Urban community; Reuse; Rainwater Harvesting; Composting; Electrical and electronic waste; Plastic

\section{Introduction}

The urban housing societies in the world, particularly in the developing countries, are becoming concrete hives for city dwellers to live in. The natural environment and greeneries get lost amidst the ever-increasing demands for greater floor areas or higher parking spaces. Generation of revenue fosters the irresponsible installation of high-paying mobile towers, which bring non-ionizing radiation right into the homes of people including elderly, children and infants. Many housing societies are facing acute water supply problems with the higher living standards of cities, and the deficit is passed on to the already meager grassy patches, plants or trees in the society premises - resulting in their slow deaths. The higher pressures of construction and deposition of construction rubbish leave the topsoil of the societies lacking fertility causing further depletion of greens. Thus, the popular practices are leading to degradation of the ambience of housing colonies and proving to be unsustainable. There are quite simple measures that can radically improve the living conditions of the housing societies without much drain of the financial resources. These require awareness, and collective responsible efforts with the infusion of some starting investments for easy implementation. In this short article, the author expresses opinion about few such aspects. These concepts have been drawn from author's experience in Indian housing colonies. However, these would be equally relevant for other housing developments of the world, where urban man could be facing similar predicaments.

\section{Rainwater Harvesting}

Depletion of ground water is a severe problem in many cities and towns. Locations experiencing heavy rainfall also face such water scarcities because of the higher surface runoff caused by the higher proportion of built-up area in the modern urban locales. One of the remedial measures could be stopping the rainwater from freely flowing into the storm sewers and down to the rivers or seas but recharging the ground water instead. This would require very little investment and could be well managed at any level, if the will to harvest rainwater is present. There are materials available on the web $[1,2]$. for easy schemes and designs to suit plots of every size. Harvesting rainwater is age-old practice in many water scarce regions, where it was stored in underground rock caverns for use all year round, for example, in Maharashtra, India. Taking lessons from the ancient, modern housing societies can seriously contribute to improvement of the ground water scenario in urban neighborhoods, consequently enhancing the local flora.

\section{Grey-Water Gardening}

A huge quantity of water discharged from the kitchen and the bathrooms of the housing societies get discharged into the sewage 
system and lost to the rivers and seas. This is called 'grey water' that can be used for flushing toilets or gardening purposes with a minimum filtering operation, thereby reducing the overall water demand of the society. For the purposes of gardening, the water may be collected by a separate pipeline, passed through some graded filter media, then stored in a tank and pumped at predecided time instances. For the purposes of toilet flushing, separate flushing tanks would be required on the building tops and the grey water may be pumped from the collection tank to the flushing tank at regular intervals for subsequent use. This would require a little more involved and expensive in installation and upkeep when compared with gardening operation. Depending upon the resources available with the housing society the managing body may decide accordingly.

\section{Biodegradable Waste Composting}

Every housing society generates a good quantity of biodegradable waste each day. There is a collection system by which these are handed over to the municipal waste trucks and get dumped in the municipal dumping ground for natural degradation or incineration as the case may be. Further, for the fertilizing the soil in the housing societies for the sake of any number of plants and trees, or the lawns of grass, the societies purchase fertile topsoil or manure from the market. This can be easily remedied by a little effort, which involves composting the biodegradable wastes within the society grounds in a systematic manner and generate rich manure for the society. This would not only be an environmentfriendly and sustainable practice, but also would be cheaper for the upkeep in the long run. There might even be opportunities for sale of manure in the market for generating revenue for the society.

\section{Abolishing Cellular Phone Tower}

Now-a-days cellular phone network is a highly competitive market and the different service providers target towards maintaining equally good, if not better, network strength in all localities as compared to their rivals. The ever-increasing competition result in high density of the towers that crowd the landscape in urban neighborhood. In an effort to reduce the expenses of putting up towers, the cellular companies target the housing societies, from whom they secure lease at much cheaper rates than what they could obtain from the commercial vendors. However, this result in high radiation in the buildings around the towers, especially the top floors below the tower and the adjacent buildings in the signal path. Cellular tower radiation has numerous harmful effects on humans and these are well documented [3-5]. The task of the housing societies to curb this menace is simply to refuse permission for setting up tower in their premises to these cellular companies and this could drastically reduce the level of the cellular tower radiation within the housing society.

\section{Electronic and Electrical Waste}

Generally, people are ignorant about the hazardous nature of the electrical and electronic waste that is generated in the present day urban lifestyle of use-and-throw on a frequent basis. Thus, they end up in disposing all their e-waste with the household waste materials, which are dumped in the municipal dumping yards. Not only the precious metals present in the e-waste are lost in the municipal waste grounds in the process of incineration or natural degradation, but there are toxic materials present in the e-waste which get into the soil, groundwater and adversely affect the flora and fauna, and also the human population in the long run [6-8]. Housing societies can generate awareness regarding this hazard and develop a program for collection of the e-waste. It would take little resources to get the electronic and electrical waste properly disposed in this manner, even if it is not recycled, but it would go a long way in educating the people and setting an excellent example for other societies to follow.

\section{Plastic Waste Management}

Plastics have been identified and accepted as one of the main contributors to non-biodegradable material, which has infiltrated into the everyday existence of humans. The management would require adoption of the policy reduce, reuse and recycle. Driven solely by the meager monies that could be earned from the waste plastic materials, presently rag-pickers take the responsibility of the recycle or reuse of plastics in majority of the locations. However, the housing societies may develop plastics management policy at individual and colony levels by educating about the recycling of plastics, as also for the reduction in their uses. The segregation of the plastics may be done at individual levels and then deposited in a common repository of the society on voluntary basis. Subsequently, they can be channelized into proper recycling processes.

\section{Conclusion}

In this article, a few areas in which little efforts from individuals and housing societies could improve the general habitability of urban communities and help them adopt sustainable and environment friendly practices have been discussed briefly. These include rainwater harvesting, grey water reuse, handling of electrical, electronic and plastic wastes, management of cellular phone towers, and composting for manure. This article expresses the opinion of the author regarding the sustainability issues for urban communities.

\section{References}

1. (2017) Rainwater Harvesting, by India Water Portal.

2. (2017) Rainwater Harvesting, by Madhya Pradesh Pollution Control Board.

3. Kumar G (2017) Cell Tower Radiation Report submitted to DOT, New Delhi, India.

4. (2017) Awareness Note on Mobile Tower Radiation and its Impact on Environment. Central Pollution Control Board, India.

5. Genuis SJ (2008) Fielding a current idea: exploring the public health impact of electromagnetic radiation. Public Health 122(2): 113-124.

6. Czuczwa JM, Hites R A (1984) Environmental fate of combustiongenerated polychlorinated dioxins and furans. Environmental Science \& Technology 18(6): 444-450. 
7. Williams E, Kahhat R, Allenby B, Kavazajian E, Kim J, et al. (2008) Environmental, social and economic implications of global reuse and recycling of personal computers Environmental Science \& Technology 42(17): 6446-6454.
8. Robinson BH (2009) E-waste: an assessment of global production and environmental impacts, Science of the Total Environment. 408(2): 183191.

\section{(C) \\ This work is licensed under Creative Commons Attribution 4.0 License}

To Submit Your Article Click Here: Submit Article

DOI: 10.32474 /TCEIA.2018.02.000147

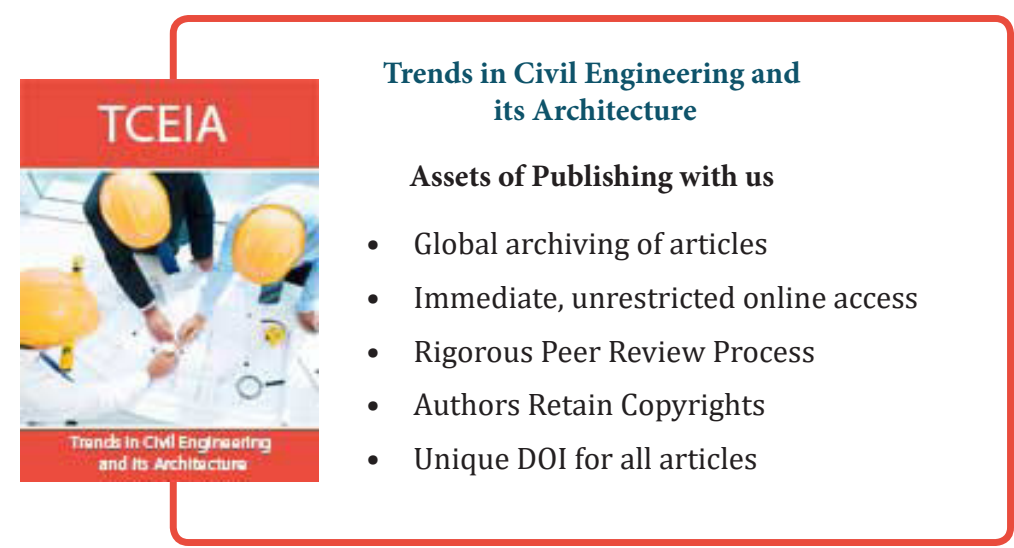

